\title{
Afrocolombianos en perspectiva histórica: La comunidad del Cacarica
}

Javier Laviña Universitat de Barcelona javierlavina@ub.edu

Recibido: Agosto de 2015

Aprobado: diciembre de 2015

\section{Introducción}

Pretendo con este trabajo hacer una aproximación, desde la historia, a la realidad de la situación por la que están pasando un conjunto importante de comunidades afrodescendientes que tras legitimar sus tierras por la ley 70 han visto como el conflicto que tiene sumida a Colombia ha recaído sobre sus territorios y se han visto obligados a refugiarse en ciudades del interior para evitar ser masacrados por los agentes enfrentados. Tomo como ejemplo la comunidad de Cacarica, en el bajo Atrato ${ }^{1}$, de los desplazados por el conflicto en el Chocó. ¿Cuál ha sido su estrategia de resistencia?, ¿de qué manera han podido sobrevivir?

\section{El cimarronaje y otras formas de resistencia.}

${ }^{1}$ Los datos de la Comunidad de Cacarica en el bajo Atrato están tomados fundamentalmente del trabajo ANGELA (Ed y comp).Somos tierra de esta tierra. Memorias de una resistencia civil. Pags. 19-23. Cacarica 2002.

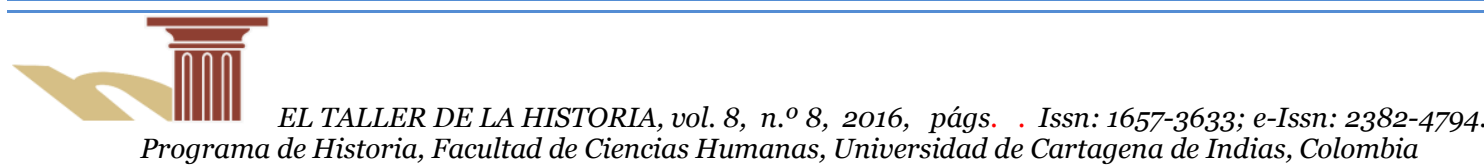


A lo largo de todo el periodo colonial los que fueron esclavizados en África y vendidos como esclavos en el Nuevo Mundo mantuvieron estrategias de resistencia a la esclavitud que les permitieron sobrevivir tanto a nivel individual como colectivo. La sumisión, aparente en muchos casos, formaba parte de la estrategia de supervivencia y humanización. Los esclavos eran animalizados por los propietarios con la finalidad de poder controlarlos mejor, sin embargo las estrategias de resistencia permitían la esclavo poder sobrevivir, por la aparente aceptación del dominio del propietario, y poder humanizarse. Los espacios en los que los esclavos estaban alejados del control de los propietarios fueron los lugares en los que los huidos se reinterpretaban y reinterpretaban sus vidas a partir de recuerdos o reconstrucciones del pasado. Estas reconstrucciones dieron como resultado un proceso de etnogénesis en el que el africano dejaba de serlo ${ }^{2}$ para reconstruirse en un nuevo medio y una nueva situación.

En algunas ocasiones estos espacios de resistencia fueron propiciados por las propias autoridades coloniales que los llevaron a América tras la experiencia que habían tenido en la metrópoli, se trataba de instituciones que reforzaban elementos identitarios de los afrodescendientes. Las cofradías de negros 3 que podían ser gené-

\footnotetext{
${ }^{2}$ Hablamos de dejar de ser africano no en que los esclavos perdieran su identidad de origen, sino que la ruptura que supuso la esclavitud les obligó a reconstruirla bajo nuevos parámetros y situaciones que, creemos, les imposibilitó mantener la identidad originaria, y les llevó a generar una nueva identidad, que sin olvidar los orígenes, se adecuaba mejor a la nueva situación.

3 Para las cofradías de negros ver Cfr. Moreno, Isidoro. La Antigua hermandad de los negros de Sevilla Etnicidad, poder y sociedad en 600 años de historia. Universidad de Sevilla, Consejeería de cultura, Junta de Andalucía. Sevilla 1997.Martín Casares, Aurelia. Cristianos musulmanes y animistas en Granada; identidades religiosas y sincretismo cultural. En Ares Queija, Berta y Stella, Alessandro. (coord.) Negros, mulatos, zambaigos. Derroteros africanos en los mundos ibéricos. pp. 207-221. Consejo Superior de Investigaciones Científicas, Sevilla, 200o.Wade, Peter. Raza y etnicidad en Latinoamérica. pag, 23.., Editorial Abya Yala, Quito 2000. Friedemann, Nina S. Cabildos de negros refugio de africana en Colombia. Montalbán n ${ }^{\circ}$ 20, pp 121-135. Universidad Católica Andrés Bello. Caracas 1998. Laviña, Javier. Sin sujeción a justicia: Iglesia, cofradías e identidad afroamericana. En García Jordán, Pilar, Gussinyer, Jordi, Izard, Miquel, Laviña, Javier, Piqueras, Ricardo, Tous, Meritxel, Zubiri Ma Teresa. Pp. 151-164. Estrategias de Poder en América Latina. Universidad de Barcelona, Barcelona 200o. Laviña, J.; Orobitg, G. Ritual y resistencia cultural en Santo Domingo. Páginas165-183. En, Resistencia y territorialidad. Culturas indígenas y afroamericanas Editorial: Universitat de Barcelona. Departament d'Antropologia Cultural i Historia d'Amèrica i África. Barcelona 2008.
} 
ricas, tan sólo de negros o de negros de nación en las que sólo se admitían a los esclavos y libertos de algún lugar concreto. Las cofradías, especialmente las de nación, se pensaban por parte de las autoridades coloniales como espacios de reunión de esclavos del mismo origen étnico que propiciaba que no hubiera unión entre los cofrades de distintos orígenes y se suponía que con esa estrategia disminuía el riesgo de sublevaciones, este espacio donde lo simbólico jugaba un papel decisivo debía servir como un elemento de control social y de disgregación de los esclavos y negros libres de las ciudades.

Las cofradías surgieron como instituciones de carácter religioso en la que los cofrades se ponían bajo la protección de un santo patrón y celebraban las fiestas y ritos en los días que les correspondían, pero que a la vez ejercían como sociedades de ayuda mutua, se encargaban de asistir a los cofrades enfermos, a las viudas y huérfanos y celebraban los funerales y entierros. Las cofradías de negros sirvieron, pues, como instituciones de integración de los esclavos y negros libres en la sociedad colonial, las cofradías se regían por ordenanzas que debían ser aprobadas por la autoridad eclesiástica y quedaban bajo la vigilancia de un clérigo que supervisaba las actividades que se llevaban a cabo durante las ceremonias.

Las cofradías tuvieron sus centros, fundamentalmente, en las ciudades donde los esclavos urbanos y los negros y pardos libres, se reunían para la celebración del culto. Pese a la vigilancia de los eclesiásticos, que estaban presentes durante la celebración de los capítulos de las cofradías, estas tuvieron una gran importancia en el mantenimiento de costumbres y rituales africanos adaptados a las nuevas circunstancias del mundo americano4. Desde este punto de vista podemos afirmar que se dio en la colonia, al menos a partir de las fuentes escritas una serie de características específicas culturales, de origen africano, pero también impregnadas de algunos elementos indígenas y europeos, y que se fueron adaptando al contexto americano y que dieron como resultado un proceso de etnogénesis ${ }^{5}$, entendido

\footnotetext{
4 Cfr. Friedemann, Nina S. Cabildos de negros refugio de africana en Colombia. Montalbán no 20. Páginas 121-135.Laviña, J. Afroamerikanischen. Feste und Toten Ritual. Páginas, 68 - 80. Comparativ, 13, $\mathrm{n}^{\mathrm{O}} 2$. Leipzig, 2003.

5 Entendemos etnogénesis como el conjunto de elementos sociales y culturales que adopta un grupo con la intención de proyectarse hacia el futuro mediante el control del horizonte social, político, cultural y económico. Esta definición va en la línea del plantamiento que hizo Guillermo Bonfil Batalla en su trabajo, La teoría del control cultural en el estudio de procesos étnicos. En Revista Papeles de la Casa Chata. Año 2, $\mathrm{N}^{\circ} 3$ pp 23-43 México 1987. Antonio Diaz Diaz. "Eurogénesis y afrogénesis. Notas para un debate" en Arocha, Jaime, (ed) Nina S. de Freidemann: cronista de disisdencias y resistencias.pp 135-145. Universidad Nacional de Colombia. Fac. De Ciencias Humanas.CES, GEA. Bogotá 2009.
} 
como la construcción social de una nueva cultura que permitió la supervivencia individual y colectiva de los descendientes de esclavos en las Américas. Las fusiones de elementos culturales de distintos grupos africanos que se dieron en América dieron lugar al surgimiento de Afroamérica como realidad cultural y social creada por los esclavos y libertos ${ }^{6} \mathrm{y}$ que ha pervivido hasta hoy.

Junto a las cofradías institución, aparentemente, católica y controlada, teóricamente, por la iglesia, los esclavizados conservaron elementos de las religiones practicadas en África que fueron importantes para el mantenimiento y la recreación de estructuras sociales entre los esclavos, mostrado una rebeldía en el espacio de lo simbólico que ha perdurado hasta la actualidad, y que se mantiene como elemento identitario y diferenciador de prácticas religiosas 7 de otros grupos, tanto originarios americanos como colonos que llegaron de España.

Pero la resistencia no sólo afectó al ámbito religioso y del espacio simbólico, sino que se dio en todos los espacios en los que se integraron los africanos como fuerza de trabajo. Resistencias al trabajo como esclavo llevaron a cientos de mujeres y hombres a huir hacia espacios, bien vírgenes, bien ocupados por comunidades indígenas, donde se refugiaron. Estos cimarrones huidos de la esclavitud fueron los que lideraron procesos de ocupación territorial en zonas, muchas veces, vacías o se reunieron con poblaciones indígenas formando nuevos grupos humanos colonizadores al margen del mundo colonial cuyo resultado fue la aparición de nuevas sociedades cimarronas, bien afrodescendientes o bien zambas que se mantuvieron durante siglos, en algunos casos, al margen de la sociedad colonial.

En la costa atlántica los cimarrones se extendieron desde la ciudad de Cartagena y resistieron los embates de los colonos y las autoridades coloniales a lo largo de dos siglos y ganaron el derecho de propiedad de sus tierras después de firmar los

6 Vide. Mintz, Sidney; Price, Richard. The birth of African-American culture: an anthropological perspective. Boston: Beacon Press, 1992

7 Arocha, Jaime. Velorios y Santos vivos. Ministerio de Cultura; Museo Nacional de Colombia. Bogotá 2008. Friedemann, Nina S; Patiño Roselli, Carlos. Lengua y sociedad en el palenque de San Basilio. Instituto Caro y Cuervo. "El canto y el baile de muerto ayudan al difunto a irse de este mundo tranquilo y contento" p 71 Bogotá 1983. Friedeman, Nina. Ma Ngombe. Guereros y ganaderos en Palenque. Carlos Valencia ed. Bogotá 1987. Schwegler. Armin. "Chima 'n "kongo". Lengua y rito ancestral en el Palenque de San Basilio (Colombia). 2 vols. ED Biblioteca ibero-americana. Frankfurt-Madrid 1996. 
acuerdos de paz con las autoridades coloniales que tuvieron que reconocer la libertad de los descendientes de los cimarrones ${ }^{8}$. Este no fue el único ejemplo de pueblo autónomo durante el periodo colonial. Surgieron otras comunidades, en Urraó, Barranca Vieja, y otros muchos, ya lejos de la memoria de la gente pero con rastros históricos en los archivos.

Los espacios cimarrones se configuraron como lugares de paz, el conflicto no estaba en el interior de la comunidad sino que venía de fuera, el conflicto siempre se resolvía en el exterior, el arcabuco era la zona de vida cimarrona, allá resolvían los conflictos, en muchas ocasiones por medio de elementos socio rituales9.

Cuando los cimarrones no tenían ventaja para el enfrentamiento la huida hacia lugares más seguros era la salida habitual, era la solución al conflicto con el exterior. Los arrochelados se trasladaban a otras áreas menos cercanas al mundo colonial, y procuraban mantenerse apartados durante un tiempo. Cuando ya se habían consolidado en el nuevo espacio, iniciaban de nuevo los contactos con el exterior, bien de forma directa, o por medio de emisarios, negros libres que ejercían de intermediaros entre el mundo colonial y los huidos. Cuando tenían la posibilidad de obtener la victoria sobre los atacantes mantenían las posiciones hasta hacer retroceder a os enemigos. Los enfrentamientos podían durar años hasta que o bien el palenque se alejaba lo suficiente como para no ser descubierto, y mantenerse sin causar problemas a los propietarios, o bien se llegaba a una situación de equilibrio en la que los representantes de la colonia firmaban la paz con los huidos.; esas fue la solución por la que optaron las autoridades coloniales con los palenques de Cartagena, la firma de la paz. En el tratado se reconocía la libertad a todos los habitantes del palenque, se les reunió en población bajo el control de un sacerdote que debía ocuparse de la enseñanza religiosa y la administración de los sacramentos, de esta forma se establecía un cierto control sobre los territorios que ocupaban los cimarrones y se aseguraban que no hubiera refugio en las comunidades pacificadas para

\footnotetext{
${ }^{8}$ Borrego Pla, María del Carmen. Palenques de negros en Cartagena de Indias a fines del siglo XVII. Escuela de Estudios Hispanoamericanos, CSIC. Sevilla.1973.

9 Friedemann, Nina. Ma N’gombé. Guerreros y ganaderos en Palenque. Pp 117-127. Carlos Valencia Editores. Bogotá 1987.
} 
nuevos cimarrones; uno de los compromisos que adquirían los ex esclavos era la entrega de cualquier nuevo cimarrón a las autoridades coloniales.

\section{Derecho y representaciones}

Las poblaciones indígenas, en muchos casos tuvieron el reconocimiento de tierras por parte de la corona y esto preservó la propiedad al menos durante la colonia y mantuvo a las comunidades, más o menos unidas y manteniendo sus formas de vida readaptadas al mundo colonial. Los indígenas, considerados seres humanos por los teólogos del XVI, mantuvieron sus formas organizativas y sociales pese a la invasión y la violencia de la conquista. Ciertamente, algunas comunidades no permanecieron en sus tierras de origen, muchas de ellas fueron desplazadas a otras áreas dentro del mismo espacio colonial, pero este desplazamiento no significó la ruptura de las comunidades sino que permanecieron unidas y se rehicieron como comunidad en las nuevas tierras, otros grupos salieron de sus tierras por la presión de la conquista y se refugiaron en zonas alejadas de los arcabuces de los conquistadores.

Desde el punto de vista político la corona reconoció la llamada "república de los indios" como entidades políticas diferenciadas del resto de los vecinos de las colonias, de manera que las comunidades indígenas mantuvieron (no sin profundas transformaciones) entidades, y representaciones políticas comunitarias que les valieron como refuerzo de la etnicidad y de usos y costumbres.

Otro elemento importante fue que ya en la época colonial la iglesia, el otro adalid de la conquista, evangelizó a las poblaciones indígenas en sus propias lenguas. Fueron muchos los catecismos escritos por religiosos en leguas indígenas, y pese a la ruptura de la cosmovisión indígena, impuesta por los conquistadores espirituales, el ocultamiento de las creencias o la cristianización de ritos permitieron que una parte de sus creencias se mantuvieran y sigan hoy todavía con cierta vigencia. Un elemento fundamental en la cosmovisión es la relación de las comunidades con la tierra, una cosmovisión no extractiva ni intensiva y el mantenimiento del equilibrio medioambiental ${ }^{10}$

10 Ver Grueso Castelblanco, Libia Rosario. El proceso organizativo de comunidades negras en el Pacífico Colombiano. para optar el Titulo de MAGISTER EN ESTUDIOS POLITICOS Asesor: Dr. 
La colonia trató de modo diferente a indígenas y afrodescendientes en la cuestión territorial, sólo si se trataba de cimarrones que hubieran firmado la paz con la corona tenían derecho a las tierras, en otros casos, pese a que se tratase de huidos del control de los propietarios no se reconocía la ocupación de las tierras. Pero las comunidades cimarronas resistentes eran intrusos sin derechos de propiedad, a ojos de las autoridades coloniales. Las relaciones entre indígenas y negros dieron un nuevo grupo humano, los zambos, que contribuyeron a sí mismo a colonizar zonas vacías de la ruta Cartagena Bogotá. Los zambos habían surgido, en muchos casos de esclavos huidos, refugiados en territorios indígenas y formaron comunidades segregadas de las indígenas.

Si los ocupantes de tierras baldías o de tierras que habían quedado vacías por la presión de los propietarios eran criollos las autoridades coloniales preferían no tomar medidas, hasta que reiteradamente la corona dictó medidas de regularización de las ocupaciones mediante el pago de un canon a la Real Hacienda, de esta forma se resolvía el problema, sin embargo si los ocupantes de tierras eran afrodescendientes libres no se les reconocía el derecho a las tierras por mucho tiempo que estuvieran trabajando en ellas ${ }^{11}$.

A lo largo del siglo XVIII se van conformando las teorías racistas que discriminaban a los habitantes de América por el color y se generó una corriente de pensamiento que jerarquizaba a los pueblos por razas y que tuvo una gran influencia en el derecho del siglo XIX.12 Las Cortes de Cádiz recogieron esta filosofía política y la gente de color quedó discriminada del derecho de ciudadanía ${ }^{13}$.

HERNANDO LLANO. Cali, Pontificia Universidad Javeriana. Facultad de Humanidades y Ciencias Sociales. Programa de Maestría en Estudios Político. Cali 2000.

${ }^{11}$ Pueblos de descendencia africana en Colombia y Ecuador: Compilación bibliográfica. Proyecto: Estudios de la Diáspora Afro-Andina. Financiado por el Convenio Andrés Bello. Universidad Andina Simón Bolívar, Sede Ecuador. 2005.

12 Garay Montañez, Nilda: «La construcción teórica de la discriminación étnica o racial en la Filosofía Política Ilustrada. Desde una perspectiva crítica», Crítica Jurídica. Revista Latinoamericana de Política, Filosofía y Derecho no 31 (2011), pp. 80-85.

13 Garay Montañez, Nilda: La idea de igualdad en el constitucionalismo español: lo racial, las castas y lo indígena en la Constitución de 1812. En. Cuadernos Constitucionales de la Cátedra Fadrique Furió Ceriol no 69/70, pp. 129-158 
Colombia recogió el mismo espíritu de la época en su concepto de ciudadanía y los negros y los pertenecientes a las llamadas castas durante el periodo colonial no fueron reconocidos en la nación reforzándose así el proceso de invisibilidad y lo que es peor la cosificación de la gente de color.

Con la abolición de la esclavitud la realidad social de la gente de color no cambió en Colombia como he marcado anteriormente las constituciones no recogieron los derechos ciudadanos de los habitantes de color, el discurso de limpieza de sangre se modernizó con la noción de ciudadano, que sólo recogía el derecho de ciudadanía para los propietarios de bienes, de manera que tanto la población indígena como la afrodescendiente quedaron excluidos de la nación.

\section{Algo de historia del Chocó}

La entrada del territorio de Chocó como parte de la realidad neogranadina se dio a partir de la presencia castellana en la costa atlántica, Alonso de Ojeda entró en tierra y fundó un caserío al que nombró San Sebastián y posteriormente se fundó la ciudad de Santa María la Antigua del Darién, una ciudad al norte de la desembocadura del Atrato.

Pedrarias Dávila llegó a la ciudad con 2000 castellanos para establecerse allá, sin embargo las circunstancias adversas y la negativa de los indígenas a trabajar para los invasores hicieron que la ciudad fuese abandonada, después de una fuerte crisis.

Pese a los abandonos el área de Urabá y el Atrato los castellanos hicieron varios intentos de establecer población en la zona, las expediciones legaron tanto desde el interior de Nueva Granada como por mar en la fachada atlántica. Pese a los intentos los establecimientos castellanos no se consolidaron, la belicosidad de los indígenas y la aparente falta de estímulos económicos llevaron al fracaso de todos los intentos de asentamiento. Sin embargo, la presencia de oro en la zona sirvió de estímulo a ingleses y franceses que mantuvieron relaciones comerciales con los caciques de la zona.

La presencia de comerciantes extranjeros estimuló los deseos de las autoridades españolas y de algunos colonos de obtener beneficios con el metal y se lanzaron a una ofensiva colonizadora para aprovechar el oro. En esta vorágine colonizadora, y pese a los conflictos y la resistencia que siempre ofrecieron los indígenas, se llega- 
ron a fundar algunos fuertes en el bajo Atrato, para impedir la entrada de extranjeros y el Real de Minas de Paravandó para controlar la explotación aurífera.

La resistencia indígena se tradujo en la salida de los Cuna hacia otras áreas fuera del contacto con los españoles y a partir de la escasez de mano de obra disponible para el trabajo de extracción aurífera se recurrió al sistema ya conocido de importar mano de obra africana para obtener el beneficio de las minas. Este poblamiento masivo de esclavos provenientes de África fue el origen de la población afrodescendiente del Chocó, ellos generaron la riqueza de la zona, trabajaron para propietarios absentistas, inversionistas que sólo se acercaban al real de minas para obtener los beneficios del trabajo de sus esclavizados ${ }^{14}$.

La minería fue un foco de atracción para pobladores que veían en la extracción de oro una oportunidad para el progreso económico, sin embargo fueron los inversionistas de Popayán los que se beneficiaron del oro. Fueron inversionistas los que acumularon riqueza por el trabajo esclavo.

La explotación de la minería tanto de veta como de lavadero se hacía por medio de cuadrillas al frente de un capataz que debía dar cuenta al concesionario de la explotación de los beneficios obtenidos. Las cuadrillas estaban compuestas por varios hombres y mujeres a cargo de un jefe, generalmente también esclavo, que organizaba el trabajo de la cuadrilla y era responsable de rendir cuentas al propietario ${ }^{15}$.

\footnotetext{
14 ANGELA (Ed y comp).Somos tierra de esta tierra. Memorias de una resistencia civil. Organización Cavida. Pags. 19-23. Cacarica 2002.

15 Jiménez, Orian. «El Chocó: Libertad y poblamiento 1750-1850». En Afrodescendientes en las Américas. Trayectorias sociales e identitarias, 150 años de abolición de la esclavitud. 121-142. ICANH, IRD, ILSA. Bogotá 2002
} 
Muchos de estos esclavos que trabajaron en la minería aurífera consiguieron la libertad, bien por compra, una forma de adquirir la libertad bastante común en el mundo urbano y minero en América, o bien por concesión de los propietarios, sin embargo, el derecho a la libertad y la ocupación y explotación de la tierra de forma comunitaria no les fue reconocido ${ }^{16}$.

Este poblamiento conformó idiosincrasia de la región que quedó bajo un relativo control de las autoridades coloniales, sin embargo, la presencia esclava reactivó las resistencias. Los indígenas y los afrodescendientes mantuvieron un pulso contra los propietarios de minas y autoridades coloniales de manera que la presencia afrodescendiente en el territorio fue conformando un tipo de ocupación que en muchos casos se convirtió en grupos cimarrones, o arrochelados, algunos pobladores, indígenas, o zambos y muchos esclavos huyeron del control de los propietarios ocupando tierras y poniéndolas en valor, pero fuera del alcance de las autoridades ${ }^{17}$.

\section{La comunidad de Cacarica}

Las comunidades de Cacarica tuvieron su origen en un primer desplazamiento que sufrieron en los años 40, durante el periodo de la violencia en Colombia,

El poblamiento del Cacarica fue a través de un primer desplazamiento de 1948 para acá, cuando nuestros antepasados les tocó salirse del Baudó y de otros sectores del Chocó hacia el bajo Atrato. Debido a la situación de violencia, que entonces se llamaba chusma, llegaron familias bastante numerosas. Era una guerra como la de hoy día, pero entonces se disputaban sólo dos partidos: el partido liberal y el partido consevador. Los liberales perseguían a los conservadores y los conservadores perseguían a los liberales...Llegaban de a pocos...Así se creó la comunidad de Bijao-Cacarica...Cuando fuimos desplazados, en toda esta área había alrededor de 33 comunidades $^{18}$.

\footnotetext{
${ }^{16}$ Arocha, Jaime. “Chocó: paraíso de paz” En: Ulloa, Astrid (ed.), Contribución africana a la cultura de las américas. Bogotá: Instituto Colombiano de Antropología-Biopacífico. 1993.

17 Hoffmann, Odile. Comunidades negras en el Pacífico colombiano. Innovaciones y dinámicas étnicas. Pp 41-49. Instituto francés de estudios andinos, Institut de recherche pour le développement, CEMCA, Abya Yala, Ciesas. Quito 2007.

18 ANGELA (Ed y comp).Somos tierra de esta tierra... Pags. 26-27. Cacarica 2002.
} 
La reacción de estos primeros ocupantes de las comunidades del Cacarica tiene mucho en común con los métodos de resistencia de los cimarrones, cuando los cimarrones eran atacados por las autoridades coloniales y los propietarios si no podían resistir el ataque se retiraba a zonas más tranquilas. Los pobladores del Baudó fueron sorprendidos por los enfrentamientos entre liberales y conservadores y decidieron mantenerse al margen del conflicto y desplazarse a zonas más tranquilas. $\mathrm{El}$ área del Cacarica resultó ser el espacio ideal. A estos primeros pobladores se les fueron uniendo campesinos procedentes de otras áreas del país que fueron en busca de tierras, porque habían sido expulsados por los terratenientes vecinos ${ }^{19}$.

Finalmente, el número de comunidades de los márgenes del río llegaron a 23, entre estas había comunidades campesinas, indígenas y afrodescendientes, que se vieron de nuevo obligadas a abandonar sus territorios en1997, con la operación Génesis.

\section{El reconocimiento de tierras}

La ley 70 reconoció la propiedad de la tierra a las comunidades del río Cacarica, pero los legisladores no calcularon las posibles situaciones que se podían desprender de este reconocimiento, podemos decir, recurriendo a las tácticas cimarronas, que el Estado había reconocido los derechos de ocupación de estas comunidades como había hecho en el periodo colonial al corona española con los cimarrones del Palenque de San Basilio.

La tierra, frontera con el parque natural Katío, con Panamá, y próximo al Darién empezó a ser apetecido por distintos sujetos, los madereros, los bananeros, los narcotraficantes, y los palmeros, y se planteó una situación similar a la que se dio en los años del caucho con la frontera peruana. Los peruanos entraron en un territorio, que nominalmente pertenecía a Colombia, para la explotación del caucho, para cuando el gobierno colombiano quiso reaccionar la situación era irreversible, sólo la guerra podía hacer desistir a Perú de los territorios anexionados. Ni el gobierno ni los inversionistas colombianos repararon en la posibilidad de explotar el caucho

\footnotetext{
19 Pulido, Alejo. Territorios frente a la minería. Debates y alternativas alrededor de la problemática minera en Colombia. CENDINS. Bogotá 2015.
} 
de las regiones fronterizas con Perú, sólo después de la ocupación pensaron en la recuperación territorial.

En el caso de las comunidades del Cacarica, ni los ganaderos, ni bananeros ni otros sujetos sociales repararon en las tierras hasta poco antes del reconocimiento de la propiedad para las comunidades, pero en esta ocasión sí pensaron en las posibilidades que ofrecían las tierras de la cuenca del Cacarica.

Desde el estado colombiano se organizó una batida militar para "acabar con un foco guerrillero de la zona" este operativo se conoció como "Operación Génesis" en 1977, según los testimonios de los supervivientes, entraron los grupos armados, y después de varias amenazas y la muerte y desaparición de algunos miembros de las comunidades fueron conminados a abandonar los asentamientos.

Los desplazados se refugiaron en Turbo, Bocas del Atrato y Panamá, los que se refugiaron en el país vecino fueron deportados a Bahía Cupica y de allí se dispersaron por el país. Los que se asentaron en Turbo padecieron condiciones insalubres y siguieron estando perseguidos por los grupos paramilitares, estas condiciones generaron un profundo desarraigo ${ }^{20}$.

En el 2002 algunos de estos afrodescendientes decidieron, con el apoyo de ONGs regresar a las comunidades, pero, se han encontrado una parte de sus campos ocupados y plantados con palma africana, utilizada para la fabricación de biodiesel.

Otro de los proyectos a los que se tienen que enfrentar es la carretera panamericana que atravesará sus territorios y que desintegraría la vida comunitaria y la relación de las comunidades con la tierra. Si a estos dos megaproyectos incluimos la presencia de grupos paramilitares la realidad es poco halagüeña para los colonos, sin embargo la organización comunitaria ha permitido el regreso y el restablecimiento de los colonos en parte de sus antiguas tierras ${ }^{21}$.

\footnotetext{
${ }^{20}$ Salazar, Yajaira; Restrepo Loaiza, Luis Hernán. Desterrados de su propio suelo. Universidad Pontífice Bolovariana. Instituto Misionero de Antropología. Facultad de Educación. 2011.

${ }^{21}$ Grueso Castelblanco, Libia Rosario. El proceso organizativo de comunidades negras en el Pacífico su colombiano. Pontificia Universidad Javeriana, Facultad de Humanidades y Ciencias Sociales. Programa de Maestría en estudios Políticos. Cali 2000.
} 
El retorno a las comunidades no ha sido fácil, desde ese año las amenazas y las desapariciones de miembros de las comunidades se han venido repitiendo acusando a los habitantes de connivencia con la guerrilla, esta escusa ha dejado impune algunos asesinatos llevados a cabo por paramilitares, que también han extorsionado a los resistentes quemando cosechas o con amenazas ${ }^{22}$.

La lucha comunitaria ha conseguido un nivel alto de organización. Han conseguido llevar a Colombia al tribunal Interamericano de Derechos Humanos donde la sentencia ha condenado al estado por alienación de derechos de los propietarios afrodescendientes, esta condena no creemos que les sirva para que les devuelvan las tierras, pero al menos tienen la victoria moral y pueden a partir de ahora iniciar los trámites de devolución frente a las autoridades judiciales colombianas.

22 Orejuela Waldo, Jeferson. Rap desde la selva, una herramienta De construcción de paz. Diplomatura de cultura de paz. Escola de cultura de pau. Junio 2008 


\section{Bibliografía.}

Angela (Ed y comp). Somos tierra de esta tierra. Memorias de una resistencia civil. Organización Cavida Cacarica 2002.

Arocha, Jaime. "Chocó: paraíso de paz” En: Ulloa, Astrid (ed.), Contribución africana a la cultura de las américas. Bogotá: Instituto Colombiano de Antropología-Biopacífico. 1993.

Arocha, Jaime. Velorios y Santos vivos. Ministerio de Cultura/Museo Nacional de Colombia. Bogotá 2008.

Bonfil Batalla, Guillermo, "La teoría del control cultural en el estudio de procesos étnicos”. En Revista Papeles de la Casa Chata. Año 2, № 3 pp 23-43 México 1987.

Borrego Pla, María del Carmen. Palenques de negros en Cartagena de Indias a fines del siglo XVII. Escuela de Estudios Hispanoamericanos, CSIC. Sevilla.1973.

Diaz Diaz, Antonio. "Eurogénesis y afrogénesis. Notas para un debate" en Arocha, Jaime, (ed) Nina S. de Freidemann: cronista de disisdencias y resistencias.pp 135-145. Universidad Nacional de Colombia. Fac. De Ciencias Humanas.CES, GEA. Bogotá 2009.

Friedeman, Nina. Ma Ngombe. Guereros y ganaderos en Palenque. Carlos Valencia ed. Bogotá 1987.

Friedemann, Nina S. Cabildos de negros refugio de africana en Colombia. Montalbán $\mathrm{n}^{\circ}$ 20. Páginas 121-135. Universidad Católica Andrés Bello. Caracas 1998.

Friedemann, Nina S; Patiño Roselli, Carlos. Lengua y sociedad en el palenque de San Basilio. Instituto Caro y Cuervo. Bogotá 1983.

Garay Montañez, Nilda: La construcción teórica de la discriminación étnica o racial en la Filosofía Política Ilustrada. Desde una perspectiva crítica, pp. 80-85. Crítica Jurídica. Revista Latinoamericana de Política, Filosofía y Derecho $\mathrm{n}^{\mathrm{o}} 31$ (2011). 
Garay Montañez, Nilda: La idea de igualdad en el constitucionalismo español: lo racial, las castas y lo indígena en la Constitución de 1812. , pp. 129-158. En. Cuadernos Constitucionales de la Cátedra Fadrique Furió Ceriol no 69/70.

Grueso Castelblanco, Libia Rosario. El proceso organizativo de comunidades negras en el Pacífico su colombiano. Pontificia Universidad Javeriana, Facultad de Humanidades y Ciencias Sociales. Programa de Maestría en estudios Políticos. Cali 2000.

Hoffmann, Odile. Comunidades negras en el Pacífico colombiano. Innovaciones y dinámicas étnicas. Instituto francés de estudios andinos, Institut de recherche pour le développement, CEMCA, Abya Yala, Ciesas. Quito 2007.

Jiménez, Orian. «El Chocó: Libertad y poblamiento 1750-1850». En Afrodescendientes en las Américas. Trayectorias sociales e identitarias, 150 años de abolición de la esclavitud. 121-142. ICANH, IRD, ILSA. Bogotá 2002

Laviña, J. Afroamerikanischen. Feste und Toten Ritual. Páginas, 68 - 80. Comparativ, 13, $\mathrm{n}^{\circ}$ 2. Leipzig, 2003.

Laviña, J.; Orobitg, G. Ritual y resistencia cultural en Santo Domingo. Páginas165183. En, Resistencia y territorialidad. Culturas indígenas y afroamericanas Editorial: Universitat de Barcelona. Departament d'Antropologia Cultural i Historia d'Amèrica i África. Barcelona 2008.

Laviña, Javier. Sin sujeción a justicia: Iglesia, cofradías e identidad afroamericana. En García Jordán, Pilar, Gussinyer, Jordi, Izard, Miquel, Laviña, Javier, Piqueras, Ricardo, Tous, Meritxel, Zubiri Ma Teresa. Pp. 151-164. Estrategias de Poder en América Latina. Universidad de Barcelona, Barcelona 2000.

Martín Casares, Aurelia. Cristianos musulmanes y animistas en Granada; identidades religiosas y sincretismo cultural. En Ares Queija, Berta y Stella, Alessandro. (coord.) Negros, mulatos, zambaigos. Derroteros africanos en los mundos ibéricos. pp. 207-221. Consejo Superior de Investigaciones Científicas, Sevilla, 2000.

Mintz, Sidney; Price, Richard. The birth of African-American culture: an anthropological perspective. Boston: Beacon Press, 1992

Moreno, Isidoro. La Antigua hermandad de los negros de Sevilla. Etnicidad, poder y sociedad en 600 años de historia. Universidad de Sevilla, Consejeería de cultura, Junta de Andalucía, Sevilla 1997.

Orejuela Waldo, Jeferson. Rap desde la selva, una herramienta De construcción de paz. Diplomatura de cultura de paz. Escola de cultura de pau Junio 2008 
Pueblos de descendencia africana en Colombia y Ecuador: Compilación bibliográfica. Proyecto: Estudios de la Diáspora Afro-Andina. Financiado por el Convenio Andrés Bello. Universidad Andina Simón Bolívar, Sede Ecuador. 2005.

Pulido, Alejo. Territorios frente a la minería. Debates y alternativas alrededor de la problemática minera en Colombia. CENDINS. Bogotá 2015.

Salazar, Yajaira; Restrepo Loaiza, Luis Hernán. Desterrados de su propio suelo. Universidad Pontífice Bolovariana. Instituto Misionero de Antropología. Facultad de Educación. 2011.

Schwegler. Armin. "Chima 'n "kongo". Lengua y rito ancestral en el Palenque de San Basilio (Colombia). 2 vols. ED Biblioteca ibero-americana. FrankfurtMadrid 1996.

Wade, Peter. Raza y etnicidad en Latinoamérica. Editorial Abya Yala, Quito200o 